\title{
Influence of Carotid Denervation on the Arousal and Cardiopulmonary Responses to Upper Airway Obstruction in Lambs
}

\author{
JAMES E. FEWELL,' BONNIE J. TAYLOR, COLLEEN S. KONDO, VICTOR DASCALU, AND \\ SONJA C. FILYK \\ Reproductive Medicine Research Group, Department of Obstetrics and Gynaecology, Medical Physiology and \\ Paediatrics, University of Calgary, Health Sciences Centre, 3330 Hospital Drive, N.W., Calgary, Alberta T2N \\ 4N1, Canada [J.E.F., C.S.K., V.D., S.C.F.] and Perinatal Research Laboratory, Department of Pediatrics, \\ University of Arkansas for Medical Sciences, 4301 West Markham Street, Little Rock, Arkansas 72205 [B.J.T.]
}

\begin{abstract}
Experiments were done on five lambs to determine if carotid denervation influences the arousal and cardiopulmonary responses to upper airway obstruction during sleep. Each lamb was anesthetized and instrumented for recordings of electrocorticogram, electro-oculogram, nuchal and diaphragm electromyograms, and measurements of arterial blood pressure and arterial $\mathrm{Hb}$ oxygen saturation. A tracheotomy was done and a fenestrated tracheotomy tube placed in the trachea. During the study, a $5 \mathrm{~F}$ balloon-tipped catheter was inserted into the tracheotomy tube so that air flow could be obstructed by inflating the balloon. No sooner than $3 \mathrm{~d}$ after surgery, measurements were made in quiet sleep and active sleep during control periods when the animal was breathing room air and during experimental periods of upper airway obstruction. Carotid denervation significantly affected the arousal response to upper airway obstruction. Arousal occurred during 14 of 14 epochs in quiet sleep and during 12 of 13 epochs in active sleep before the arterial $\mathrm{Hb}$ oxygen saturation decreased to $30 \%$. However, the time to arousal was increased and the arterial $\mathrm{Hb}$ oxygen saturation at arousal was decreased in carotid-denervated lambs compared with what we have previously observed in carotid-intact lambs. These data provide evidence that the carotid chemoreceptors and/or carotid baroreceptors play a major role in causing arousal from sleep during upper airway obstruction in lambs. Our results may have implications for sudden infant death syndrome, because it is possible that alterations in the arousal response to respiratory stimuli play a role in sudden infant death. (Pediatr Res 28: 374-378, 1990)
\end{abstract}

The arousal response from sleep is an important protective response that may prevent severe hypoxemia and death during an apneic episode. This may be particularly evident during obstructive apnea, as restoration of upper airway patency and resumption of tidal ventilation are generally believed to be preceded by arousal from sleep (1-4). In newborn humans, Stark

Received May 19, 1989; accepted May 31, 1990.

Correspondence and reprint requests: James E. Fewell, Ph.D., Heritage Medical Research Building, \#206, University of Calgary, 3330 Hospital Drive, N.W. Calgary, Alberta T2N 4N1, Canada.

Supported by U.S. Public Health Services Grants HL34377, HD24018, The Alberta Heritage Foundation for Medical Research, and The Nat Christie Unit for the Study of Human Reproduction.

J.E.F. is an Established Investigator of the American Heart Association and a Heritage Medical Scholar of the Alberta Heritage Foundation for Medical Research. and Thach (5) found that arousal affected the pattern of restoration of airflow during upper airway obstruction produced by neck flexion. In the absence of arousal, reopening of the airway was delayed and incomplete. In contrast, when arousal did occur, reopening of the airway was immediate and complete.

Previous experiments on young lambs have demonstrated that upper airway obstruction causes arousal from sleep (6-9), but the precise mechanism of the arousal response is unknown. Upper airway obstruction not only produces large changes in pleural and airway pressure, but also produces arterial hypoxemia and hypercarbia. Our previous experiments have shown that arousal from quiet sleep during upper airway obstruction occurs before any significant changes in the arterial $\mathrm{Hb}$ oxygen saturation, and that the arousal response is only minimally delayed by inhalation of $60 \%$ oxygen before upper airway obstruction (8). In contrast, arousal from active sleep during upper airway obstruction occurs after significant decreases in the arterial $\mathrm{Hb}$ oxygen saturation and the response is significantly delayed by inhalation of $60 \%$ oxygen before upper airway obstruction (8). However, arousal from active sleep during upper airway obstruction occurs at a higher arterial $\mathrm{Hb}$ oxygen saturation than does arousal from active sleep during alveolar hypoxia alone (10) or during a combination of alveolar hypoxia and hypercarbia in young lambs (11).

Both arterial hypoxemia (10) and hypercarbia (12) alone are capable of causing arousal from sleep in young lambs. The arousal response to these stimuli is significantly delayed after carotid denervation $(13,14)$. If the arousal response to upper airway obstruction results primarily from arterial hypoxemia and/or hypercarbia, it should be significantly delayed after carotid denervation. Thus, the purpose of our experiments was to investigate the effect of carotid denervation on the arousal response from sleep to upper airway obstruction in young lambs.

\section{MATERIALS AND METHODS}

Five lambs ranging in age from 11 to $24 \mathrm{~d}$ were studied. Each lamb was separated from its mother 3 to $7 \mathrm{~d}$ after birth and was housed in our laboratory in a Plexiglas cage with continuous access to milk (Lamb Milk Replacer, Land O' Lakes, Inc., Fort Dodge, IA). The lambs were kept among other lambs, fed and slept ad libitum, and soon became accustomed to the surroundings and laboratory personnel.

Surgical preparation. Each lamb underwent one operation before study. For surgery, each lamb was given atropine sulfate $(0.2 \mathrm{mg} / \mathrm{kg}$ s.c. $)$ and anesthesia was induced by having the lamb breathe 3 to $4 \%$ halothane in oxygen via a mask. Its trachea was then intubated with a cuffed endotracheal tube, and anesthesia was maintained by ventilating the lamb's lungs with 0.5 to $1.0 \%$ 
halothane in oxygen. An ECG, end-tidal carbon dioxide levels, and rectal temperature were monitored during surgery; body temperature was kept near $39^{\circ} \mathrm{C}$ with a heating pad and endtidal carbon dioxide levels were kept near $5 \%$ with a volumecycled ventilator.

The operation was done when the lamb was between 7 and 21 $\mathrm{d}$ of age. A double-lumen fiberoptic catheter oximeter (model U440 Opticath, Oximetrix, Inc., Mountain View, CA; $90 \%$ response to a step change in arterial oxygen saturation within 5 s) was inserted to the thoracic aorta via a femoral artery for continuous measurement of arterial $\mathrm{Hb}$ oxygen saturation and blood pressure. Electrodes for the following recordings were also implanted: electrocorticogram (recorded from electrodes placed through burr holes to lie over the parietal cortex), electro-oculogram (recorded from electrodes placed at the inner and outer canthus of the right eye), nuchal electromyogram (recorded from electrodes placed in the dorsal cervical musculature), and diaphragm electromyogram (recorded from electrodes placed transabdominally into muscle fibers adjacent to the lateral margin of the central tendon of the right hemidiaphragm). A reference wire was sutured into the s.c. tissue of the scalp. The electrodes were made in our laboratory and were paired, Teflon-coated, multistranded stainless steel wires (AS 633, Cooner Wire Co., Chatsworth, CA); approximately $3 \mathrm{~mm}$ of the tip of each was bared for implantation. The proximal end of each wire was bared and soldered to the appropriate pin of an 18-pin electrical plug, which was interfaced with four differential high-impedance probes (7HIP5G, Grass Medical Instruments, Quincy, MA) during the study.

Carotid denervation was performed as follows. The carotid body and carotid sinus were approached as described by Appleton and Waites (15) and denervated as described by Bureau $e$ al. (16). Briefly, the denervation procedure consisted of: 1) cutting the sinus nerve, 2) stripping the adventitia from the wall of the carotid artery from the origin of the lingual artery to 0.5 $\mathrm{cm}$ below the origin of the occipital artery, 3) removing all fibroadipose nodular tissue from around the occipital-carotid artery junction, 4) sectioning all minute vessels arising in the area of the carotid and occipital artery bifurcation, 5) stripping the adventitia from the wall of the occipital artery for $1 \mathrm{~cm}$ from its origin from the carotid artery, and 6) painting the walls of the stripped vessels with $7 \%$ phenol.

A tracheotomy was also performed and a fenestrated tracheostomy tube (Shiley, Inc., Irvine, CA) placed in the trachea (7). This tracheostomy tube allows one to select whether an animal breathes entirely through the opening of the tracheostomy tube (cuff inflated, inner cannula in place) or entirely through its upper airway (cuff inflated, decannulation cannula in place). After surgery, the decannulation cannula was inserted into the tracheostomy tube so that airflow during tidal respiration would be through the upper airway. The lambs were allowed to recover from surgery in a Shor-Line intensive care unit for small animals (Schroer Manufacturing Company, Kansas City, MO) and were then placed back in their Plexiglas study cage in our sleep laboratory, but were not studied before the 3rd postoperative day. The lambs received antibiotics daily, (penicillin $G$ and dihydrostreptomycin) beginning on the day of surgery.

Conditions of observations. Our sleep laboratory consists of a large room that contains two sound-attenuating chambers. Temperature, sound, and lighting could be precisely controlled in each chamber. The lambs in this series of experiments were raised in an environmental temperature of $25 \pm 1{ }^{\circ} \mathrm{C}$. Each chamber also had a one-way viewing mirror as well as a closed circuit video system to observe the lambs. Our recording equipment was kept in the room adjacent to the chamber. Before the study, a partition was placed in the cage to prevent the lamb from turning around once the catheter, electrode, and breathing circuit were connected. However, the lamb could still lay down, stand up, and feed ad libitum.

For the study, the vascular catheter was connected to a strain- gauge manometer (Gould P23ID, Gould, Inc., Oxnard, CA) using rigid pressure-monitoring tubing, and the optical connector was connected to the optical module of the oximeter processor; the strain-gauge manometer was placed at the approximate level of the heart when the animal was lying down. The inner cannula was placed into the tracheostomy tube and a breathing circuit (Neonatal Ventilator Circuit, model 5302, Intec Medical Inc., Blue Springs, MO) attached so that $10 \mathrm{~L} / \mathrm{min}$ of a known gas (i.e. room air) could be passed by the tracheostomy tube. The tip of a balloon-tipped catheter (5 F Swan-Ganz, Edwards Laboratory Inc., Anasco, Puerto Rico) was placed through the Tpiece of the breathing circuit into the body of the tracheostomy tube so that airflow could be obstructed by inflating the balloon. The 18-pin electrical plug was connected to the differential high impedance probes; a heavy duty cable connected the differential high impedance probes to A.C. preamplifiers (model 7P5 Wide Band A.C. EEG Pre-amplifier, Grass Medical Instruments) in the adjacent room. The electrophysiologic signals were high-pass filtered using the $1 / 2$-amplitude low-frequency response control on the A.C. preamplifiers (electrocorticogram $1.0 \mathrm{~Hz}$, electrooculogram $0.3 \mathrm{~Hz}$, and electromyograms $3 \mathrm{~Hz}$ ). The amplified activity from the electrocorticogram was full-wave rectified and then integrated (model 7P10 Polygraph Integrator, Grass Medical Instruments) to give a running record of the total accumulated area under the electrocortical waves (10). The tracing wrote out a ramp function, the slope of which was directly proportional to the ongoing input activity.

The following electrophysiologic criteria were used to define behavioral state once the animal was lying down (10). During quiet wakefulness, the electrocorticogram showed a fast wavelow voltage pattern; there were occasional eye movements and there was tonic activity on the nuchal electromyogram. During quiet sleep, the electrocorticogram showed a slow wave-high voltage pattern; there were no eye movements and there was tonic activity on the nuchal electromyogram. During active sleep, the electrocorticogram showed a fast wave-low voltage pattern; there were rapid eye movements on the electro-oculogram; there was no activity on the nuchal electromyogram and there were occasional fast ear, facial, and limb twitches. Each lamb was allowed to cycle through at least one epoch of quiet sleep before the experiment actually began so that we could determine the amplitude of the integrated electrocortical activity and set strict criteria for defining quiet sleep.

The following electrophysiologic criteria were used to define arousal from sleep. During quiet sleep, the point of arousal was determined by a change in the electrocorticogram from a high voltage-slow wave pattern to a low voltage-fast wave pattern with continued activity on the nuchal electromyogram (10). During active sleep, the point of arousal was determined by a return of tonic activity on the nuchal electromyogram with continued low voltage-fast wave activity on the electrocorticogram.

Experimental protocol. During the study, systemic arterial blood pressure, arterial $\mathrm{Hb}$ oxygen saturation, and the electrophysiologic signals were recorded on a Grass model 7 polygraph (Grass Medical Instruments) and the lambs were monitored on a closed-circuit video system. Measurements were made during 30 -s control periods when the lambs were breathing room air and during experimental periods of upper airway obstruction. Upper airway obstruction was terminated during an experimental period by deflating the balloon once the animal aroused from sleep. If an animal did not arouse before the arterial $\mathrm{Hb}$ saturation decreased to $30 \%$, the experimental period was terminated. Because the mean epoch lengths of quiet sleep and active sleep of chronically instrumented lambs during this age range are 6 to $7 \mathrm{~min}$ and 3 to $4 \mathrm{~min}$, respectively (Johnson $\mathrm{P}$, unpublished observations), control measurements were made approximately 2 to $3 \mathrm{~min}$ after the lamb entered quiet sleep and approximately $30 \mathrm{~s}$ after the lamb entered active sleep. Experiments began between 0800 and $1000 \mathrm{~h}$ and continued until sufficient data were collected. Some of the animals also participated in experi- 
ments to investigate the influence of carotid denervation on the arousal and cardiopulmonary responses to alveolar hypoxia and alveolar hypercapnia. When this occurred, the sequence of the individual experiments was randomized and the experiments were separated by at least $24 \mathrm{~h}$. During the aforementioned experiments, the animals were exposed to alveolar hypoxemia or alveolar hypercapnia only six times during an experiment.

Statistical analysis. For every animal, we determined an average value for each variable during the control period and during the experimental period immediately preceding arousal from quiet sleep and active sleep. If an animal did not arouse before the arterial $\mathrm{Hb}$ oxygen saturation decreased to $30 \%$, the values obtained immediately preceding the development of an arteria $\mathrm{Hb}$ oxygen saturation of $30 \%$ were used. To analyze the data statistically, we performed a two-factor analysis of variance for repeated measures of the same variable to determine if state (quiet sleep versus active sleep) or period (control versus experimental) affected arterial $\mathrm{Hb}$ oxygen saturation, heart rate, systolic blood pressure, diastolic blood pressure, or respiratory frequency (17). If there was a significant difference, a Duncan's multiple comparison test was performed to determine which means were statistically different (18).

In addition, because arousal was delayed after carotid denervation, we determined an average value for each variable at 4-6 $s$ into the experimental period for quiet sleep and at 16-18 s into the experimental period for active sleep; $6 \pm 2$ and $18 \pm 5 \mathrm{~s}$ are the times (mean $\pm 1 \mathrm{SD}$ ) to arousal from quiet sleep and active sleep, respectively, during upper airway obstruction in carotidintact young lambs [upper airway obstructions before sleep fragmentation, $n=5$ (7); upper airway obstructions during inhalation of room air, $n=8(8)$; 1st three upper airway obstructions in each sleep state, $n=5(9)$ ]. Data from these time periods allowed us to compare the cardiorespiratory responses to upper airway obstruction obtained from carotid-denervated lambs (present study) with those obtained from carotid-intact young lambs (79). We performed a three-factor analysis of variance for repeated measures of the same variable to determine if group (denervated versus intact), period (control versus experimental), or state (quiet sleep versus active sleep) affected arterial $\mathrm{Hb}$ oxygen saturation, heart rate, systolic blood pressure, diastolic blood pressure, or respiratory frequency (17). If there was a significant difference, a Duncan's multiple comparison test was performed to determine which means were statistically different (18).

\section{RESULTS}

Carotid denervation significantly influenced the arousal and cardiopulmonary responses to upper airway obstruction. Although arousal occurred during 14 of 14 epochs in quiet sleep (data are from three occlusions in four animals and two occlusions in one animal) and during 12 of 13 epochs in active sleep (data are from three occlusions in three animals and two occlusions in two animals), the time to arousal was increased and the arterial $\mathrm{Hb}$ oxygen saturation at arousal was decreased in carotiddenervated lambs compared with the responses we have previously observed in carotid-intact lambs (Tables 1 and 2). The time to arousal was $19 \pm 9 \mathrm{~s}$ during quiet sleep and $49 \pm 8 \mathrm{~s}$ during active sleep in carotid-denervated lambs compared with $6 \pm 2 \mathrm{~s}$ during quiet sleep and $18 \pm 5 \mathrm{~s}$ during active sleep in carotidintact lambs (7-9).

Carotid-denervation affected baseline cardiorespiratory variables. Systolic blood pressure was increased and respiratory frequency was decreased in carotid-denervated lambs compared with carotid-intact lambs (Table 2) in both quiet sleep and active sleep. Carotid denervation also attenuated the heart rate response to upper airway obstruction. Arterial blood gases and $\mathrm{pH}$ during quiet wakefulness were as follows: $\mathrm{pH}, 7.37 \pm 0.02$; arterial oxygen tension, $8.9 \pm 1.3 \mathrm{kPa}$ (67 \pm 10 torr); and arterial carbon dioxide tension, $7.2 \pm 0.3 \mathrm{kPa}$ (54 \pm 2 torr).

\section{DISCUSSION}

Our study provides new information about the mechanism of arousal from sleep in response to cardiorespiratory stimuli in lambs. The data provide evidence that the carotid body and/or the carotid sinus play a major role in causing arousal from sleep during upper airway obstruction. Furthermore, carotid denervation significantly affected baseline cardiorespiratory control as well as the cardiorespiratory response to upper airway obstruction.

Carotid denervation significantly affected the arousal response to upper airway obstruction. Arousal occurred during 14 of 14 epochs in quiet sleep and during 12 of 13 epochs in active sleep before the arterial $\mathrm{Hb}$ oxygen saturation decreased to $30 \%$. However, the time to arousal was increased and the arterial $\mathrm{Hb}$ oxygen saturation at arousal was decreased in carotid-denervated lambs compared with the responses we have previously observed in carotid-intact lambs (7-9). Our present data suggest that the carotid chemoreceptors may play a more important role in initiating the arousal response to upper airway obstruction during quiet sleep than we have previously realized.

Our previous experiments have shown that arousal from quiet sleep during upper airway obstruction occurs before any significant changes in the arterial $\mathrm{Hb}$ oxygen saturation (6), and that the arousal response is only minimally delayed by inhalation of $60 \%$ oxygen before obstruction (8). From these data, we suggested that other factors-such as lung and chest wall mechanoreceptors-play a major role in initiating arousal from quiet sleep during upper airway obstruction. Although it appears that hypoxemia plays a more important role in initiating the response than we previously realized, we still contend that factors other than hypoxemia and hypercapnia play a role in initiating arousal from quiet sleep during upper airway obstruction for the following reasons. In our present study, arousal occurred during quiet sleep when the arterial $\mathrm{Hb}$ oxygen saturation decreased from 79 $\pm 7 \%$ (mean $\pm 1 \mathrm{SD}$ ) to $69 \pm 9 \%$ during upper airway obstruction (Table 1). In a previous study (13), we found that arousal occurred during only four of 11 epochs of quiet sleep before the arterial $\mathrm{Hb}$ oxygen saturation decreased to $30 \%$ during inhalation of $5 \%$ oxygen in carotid-denervated lambs; this is in marked contrast to what we have observed in carotid-intact lambs (10). In addition, we have also found that arousal occurred during only six of 12 epochs of quiet sleep within 2 min during inhalation of $10 \%$ carbon dioxide in carotid-denervated lambs (14); this again, is in marked contrast to what we have observed in carotid-intact lambs (12). Furthermore, we have reported that an arousal response decrement develops during both quiet sleep and active sleep after repeated exposure to rapidly developing hypoxemia (i.e. inhalation of $5 \%$ oxygen) (19), but develops only during active sleep after repeated exposure to upper airway obstruction (9). These data would allow one to suggest that other factors $(e . g$. lung and chest wall mechanoreceptors) also participate in initiating the arousal response to upper airway obstruction during quiet sleep in lambs.

Our results on the arousal response are in general agreement with those of Bowes et al. (20), who found that carotid denervation had a profound effect on the arousal response to upper airway obstruction with arousal failing to occur despite arterial $\mathrm{Hb}$ oxygen saturations $<60 \%$ in quiet sleep and $<50 \%$ in active sleep in two adult dogs. Arousal occurred in arterial $\mathrm{Hb}$ oxygen saturations of $89 \pm 3$ (mean $\pm 1 \mathrm{SE}$ ) and $85 \pm 4 \%$ in quiet sleep and active sleep, respectively, in the intact dogs. Bowes et al. (20) also found that vagal blockade produced a small decrement in the arousal response to upper airway obstruction during quiet sleep in two adult dogs.

It is important to point out that our carotid denervation procedure, as well as that of Bowes et al. (20), eliminated afferents not only from the carotid chemoreceptors but also from the carotid baroreceptors. We have previously reported that acute increases in blood pressure cause arousal from sleep in lambs 
Table 1. Arousal and cardiorespiratory responses to upper airway obstruction in carotid-denervated young lambs during quiet sleep and active sleep*

\begin{tabular}{|c|c|c|c|c|c|c|}
\hline \multirow[b]{2}{*}{ Variable } & \multicolumn{3}{|c|}{ Quiet sleep } & \multicolumn{3}{|c|}{ Active sleep } \\
\hline & Control & & Experimental & Control & & Experimental \\
\hline Arterial oxygen saturation (\%) & $79 \pm 7$ & $\dagger$ & $69 \pm 9$ & $81 \pm 7$ & $\dagger$ & $45 \pm 9$ \\
\hline Heart rate (beats/min) & $\$ 193 \pm 20$ & $\dagger$ & $168 \pm 20$ & $161 \pm 30$ & & $146 \pm 27$ \\
\hline Systolic blood pressure $(\mathrm{mm} \mathrm{Hg}$ ) & $107 \pm 14$ & $\dagger$ & $132 \pm 17$ & $107 \pm 14$ & $\dagger$ & $158 \pm 27$ \\
\hline Diastolic blood pressure (mm $\mathrm{Hg})$ & $68 \pm 5$ & & $74 \pm 8$ & $62 \pm 9$ & $\dagger$ & $89 \pm 26$ \\
\hline Respiratory frequency (breaths/min) & $31 \pm 6$ & & $26 \pm 7$ & $35 \pm 8$ & $\dagger$ & $24 \pm 11$ \\
\hline
\end{tabular}

* Values are means \pm 1 SD. Experimental measurements were made immediately preceding arousal; if arousal did not occur before an arterial oxygen saturation of $30 \%$, measurements were made immediately preceding development of an arterial oxygen satuation of $30 \%$. A value of $30 \%$ was used for arterial oxygen saturation during the experimental period if arousal did not occur.

$\dagger p<0.05$ for control $v s$ experimental period for a given sleep state.

$\$ p<0.05$ for quiet sleep $v s$ active sleep for a given variable during the control period as determined by analysis of variance and Duncan's multiple comparison.test.

Table 2. Comparison of cardiovascular and respiratory responses to upper airway obstruction in carotid-intact (I) and carotiddenervated (D) young lambs during quiet sleep and active sleep*

\begin{tabular}{|c|c|c|c|c|c|c|c|}
\hline \multirow{2}{*}{ Variable } & \multirow[b]{2}{*}{ Group } & \multicolumn{3}{|c|}{ Quiet sleep } & \multicolumn{3}{|c|}{ Active sleep } \\
\hline & & Control & & $4-6 s$ & Control & & $16-18 \mathrm{~s}$ \\
\hline Arterial oxygen saturation (\%) & $\mathrm{I}$ & $\begin{array}{c}91 \pm 5 \\
\stackrel{\ddagger}{79} \pm\end{array}$ & & $\begin{array}{c}89 \pm 7 \\
\vdots \\
78 \pm 6\end{array}$ & $\begin{array}{c}92 \pm 3 \\
\stackrel{ \pm}{ \pm}+6\end{array}$ & $\dagger$ & $\begin{array}{c}79 \pm 9 \\
\vdots \\
70 \pm 8\end{array}$ \\
\hline Heart rate (beats/min) & I & $\begin{array}{l}\S 180 \pm 14 \\
\S 193 \pm 20\end{array}$ & $\dagger$ & $\begin{array}{c}165 \pm 15 \\
\ddagger \\
184 \pm 17\end{array}$ & $\begin{array}{l}157 \pm 14 \\
161 \pm 30\end{array}$ & $\dagger$ & $\begin{array}{c}117 \pm 29 \\
\ddagger \\
153 \pm 19\end{array}$ \\
\hline Systolic blood pressure $(\mathrm{mm} \mathrm{Hg})$ & I & $\begin{array}{c}\S 101 \pm 11 \\
\ddagger \\
107 \pm 14\end{array}$ & $\dagger$ & $\begin{array}{l}105 \pm 13 \\
107 \pm 13\end{array}$ & $\begin{array}{c}95 \pm 14 \\
\ddagger \\
107 \pm 14\end{array}$ & $\dagger$ & $\begin{array}{c}98 \pm 14 \\
\div \\
114 \pm 12\end{array}$ \\
\hline Diastolic blood pressure $(\mathrm{mm} \mathrm{Hg})$ & $\mathrm{I}$ & $\begin{array}{l}\S 71 \pm 11 \\
\S 68 \pm 5\end{array}$ & & $\begin{array}{c}72 \pm 11 \\
\stackrel{\ddagger}{ } \\
67 \pm 4\end{array}$ & $\begin{array}{l}67 \pm 11 \\
65 \pm 9\end{array}$ & $\dagger$ & $\begin{array}{l}64 \pm 8 \\
67 \pm 8\end{array}$ \\
\hline Respiratory frequency (breaths/min) & $\begin{array}{l}\mathrm{I} \\
\mathrm{D}\end{array}$ & $\begin{array}{c}839 \pm 7 \\
+ \\
31 \pm 6\end{array}$ & $\dagger$ & $\begin{array}{l}32 \pm 7 \\
28 \pm 16\end{array}$ & $\begin{array}{c}50 \pm 10 \\
\ddagger \\
35 \pm 8\end{array}$ & $\dagger$ & $\begin{array}{c}40 \pm 6 \\
\ddagger \\
23 \pm 8\end{array}$ \\
\hline
\end{tabular}

* Values are means \pm 1 SD. $n=18$ for carotid-intact animals (7-9) and $n=5$ for carotid-denervated animals. Experimental measurements were made at $4-6 \mathrm{~s}$ in quiet sleep and $16-18 \mathrm{~s}$ in active sleep.

$\dagger p<0.05$ for control $v s$ experimental period for a given sleep state and group.

$\ddagger p<0.05$ for intact $v s$ denervated for a given sleep state and period.

$\S p<0.05$ for quiet sleep $v s$ active sleep for a given group during the control period as determined by analysis of variance and Duncan's multiple comparison test.

(21) and Horne et al. (22) have recently reported that the arousal response to an acute increase in blood pressure is abolished by sino-aortic denervation in lambs. Inasmuch as an increase in blood pressure does occur before arousal during upper airway obstruction in carotid-intact lambs (Table 2), it is possible that the carotid baroreceptors play a role in initiating the arousal response to upper airway obstruction. The effectiveness of our carotid denervation procedure is provided by several lines of evidence. First, hypoventilation and hypoxemia were observed during resting conditions in carotid-denervated animals, but not in carotid-intact animals. This has been observed in other species [e.g. cat (23), dog (20), piglet (24)] and provides evidence that the peripheral chemoreceptors play a role in regulating the arterial carbon dioxide tension as well as the arterial oxygen tension. Second, the early respiratory frequency response to rapidly developing hypoxemia was eliminated as compared with the response in carotid-intact animals (13). Third, systemic arterial hypertension was observed during resting conditions (Table 2).
It is also interesting to note that carotid denervation significantly attenuated the heart rate response to upper airway obstruction as compared with that observed in carotid-intact lambs (Table 2).

The arousal response from sleep has been suggested to be an important protective response that may prevent severe hypoxemia and death during an apneic episode (25). Although apnea occurs to some extent in almost all preterm (26) and term infants (27), little is known about the mechanism that terminates an apneic episode. Guntheroth (28) has suggested that normal infants do not die because they have an intact arousal response and has hypothesized that the crucial area of abnormal physiology in sudden infant death syndrome is arousal responsiveness. The importance of the arousal response is at least 2-fold. First, wakefulness per se is a potent stimulus to breathing. Second, arousal permits the initiation of behavioral and ventilatory response to the stimulus; arousal is generally thought to precede resumption of tidal ventilation during apnea (1-4). 
Two recent studies have provided evidence of an abnormal arousal response to hypoxemia in infants who have had an apparent life-threatening event $(29,30)$. Although these data might support the hypothesis that an abnormal arousal response to hypoxemia plays a role in the final pathway to the sudden infant death syndrome, one also has to implicate failure of other "backup" mechanism(s) (e.g. gasping or circulatory failure), inasmuch as these infants did not die (31).

The results of our studies may have implications for sudden infant death syndrome. If the final event is apnea, as has been hypothesized $(28,32)$, data from our previous studies would allow one to speculate that: $l$ ) if the rate of change of arterial oxygen is great enough during apnea in active sleep, arousal may fail to occur before electrocortical signs of cerebral hypoxia and primary apnea occur (10) and 2 ) if an infant is repeatedly exposed to hypoxemia-either as a result of multiple apneic episodes (9) or hypoxemia during sleep as a result of gas exchange abnormalities or cardiorespiratory control abnormalities (19)-the arousal response to apnea might be impaired. Furthermore, data from our present study would allow one to speculate that if carotid chemoreceptor and/or carotid baroreceptor function is impaired, arousal may fail to occur before hypoxic cerebral depression occurs. If, in addition, there is a deficit in the gasping mechanism or if the circulation fails before the onset of gasping, death could quickly ensue.

\section{REFERENCES}

1. Gastaut H. Tassinari CA. Duron B 1966 Polygraphic study of the episodic diurnal and nocturnal (hypnic and respiratory) manifestations of the Pickwickian Syndrome. Brain Res 2:167-186

2. Walsh RE, Michealson ED, Harkerload LE, Zichelboim A, Sackner MA 1972 Upper airway obstruction in obese patients with sleep disturbances and somnolence. Ann Intern Med 76:185-192

3. Remmers JE, DeGroot WJ, Sauerland EK, Anch AM 1978 Pathogenesis of upper airway occlusion during sleep. J Appl Physiol 44:931-938

4. Frank Y, Kravath RE, Pollak CP, Weitzman ED 1983 Obstructive sleep apnea and its therapy: clinical and polysomnographic manifestations. Pediatrics $71: 737-740$

5. Stark AR, Thach BT 1981 Recovery of airway patency after obstruction in normal infants. Am Rev Respir Dis 123:691-693

6. Fewell JE 1985 Arousal and cardiorespiratory responses to upper airway obstruction during sleep in lambs. In: Jones CT, Nathanielsz PW (eds) The Physiological Development of the Fetus and Newborn. Academic Press, London, pp 217-222

7. Fewell JE 1987 The effect of short-term sleep fragmentation produced by intense auditory stimuli on the arousal response to upper airway obstruction in lambs. J Dev Physiol 9:409-417

8. Baker SB, Fewell JE 1987 Effect of hyperoxia on the arousal response to upper airway obstruction. Pediatr Res 21:116-120

9. Fewell JE, Williams BJ, Szabo JS, Taylor BT 1988 Influence of repeated upper airway obstruction on the arousal and cardiopulmonary response to upper airway obstruction in lambs. Pediatr Res 23:191-195
10. Fewell JE, Baker SB 1987 Arousal response to rapidly developing hypoxemia in lambs. Pediatr Res 22:471-477

11. Fewell JE, Konduri GK 1988 Repeated exposure to rapidly developing hypoxemia influences the interaction between oxygen and carbon dioxide in initiating arousal from sleep in lambs. Pediatr Res 24:28-33

12. Fewell JE, Baker SB 1989 Arousal and cardiopulmonary responses to hyperoxic hypercapnia in lambs. J Dev Physiol 12:21-26

13. Fewell JE, Kondo CS, Dascalu V, Filyk SC 1989 Influence of carotid denervation on the arousal and cardiopulmonary responses to rapidly developing hypoxemia in lambs. Pediatr Res 25:473-477

14. Fewell JE, Kondo CS, Dascalu V, Filyk SC 1989 Influence of carotid-denervation on the arousal and cardiopulmonary responses to hypercapnia in lambs. J Dev Physiol 12:193-199

15. Appleton AB, Waites GMH 1957 A surgical approach to the superior cervical ganglion and related structures in the sheep. J Physiol 135:52-57

16. Bureau MA, Lamarche J, Foulon P, Dalle D 1985 Postnatal maturation of respiration in intact and carotid body-chemodenervated lambs. $J$ Appl Physiol 59:869-874

17. Winer BJ 1971 Single-factor experiments having repeated measures on the same elements. In: Statistical Principles in Experimental Design. McGrawHill, New York, pp 261-308

18. Zar JH 1979 Multiple comparisons. In: Biostatistical Analyses. Prentice-Hall, Englewood Cliffs, NJ, pp 151-162

19. Fewell JE, Konduri GK 1989 Influence of repeated exposure to rapidly developing hypoxemia on the arousal and cardiopulmonary response to rapidly developing hypoxemia in lambs. J Dev Physiol 11:77-82

20. Bowes G, Townsend ER, Bromley SM, Kozar LF, Phillipson EA 1981 Role of the carotid body and of afferent vagal stimuli in the arousal response to airway occlusion in sleeping dogs. Am Rev Respir Dis 123:644-647

21. Fewell JE, Johnson P 1984 Acute increases in blood pressure cause arousal from sleep in lambs. Brain Res 311:259-265

22. Horne RSC, Berger PJ, de Preu N, Walker AM 1988 Arousal responses to hypertension in newborn lambs are abolished by sinoaortic denervation. Proceedings of the Society for the Study of Fetal Physiology, p 24

23. Guazzi M, Freia ED 1969 Sino-aortic reflexes and arterial $\mathrm{pH}, \mathrm{PO}_{2}$ and $\mathrm{PCO}_{2}$ in wakefulness and sleep. Am J Physiol 217:1623-1627

24. Haddad GG, Donnelly DF 1988 The interaction of chemoreceptors and baroreceptors with the central nervous system. A critical role in early life. Ann NY Acad Sci 533:221-227

25. Phillipson EA, Sullivan CE 1978 Arousal: the forgotten response to respiratory stimuli. Am Rev Respir Dis 118:807-809

26. Read DJC, Henderson-Smart DJ 1984 Regulation of breathing in the newborn during different behavioral states. Annu Rev Physiol 46:675-685

27. Southall DP, Richards J, Brown DJ, Johnston PGB, DeSwiet M, Shinebourne EA 1980 24-hour recordings of ECG and respiration in the newborn infant with findings related to sudden death and unexplained brain damage in infancy. Arch Dis Child 55:7-16

28. Guntheroth WG 1983 Arrhythmia, apnea or arousal? In: Tildon WT, Rolder LM, Steinschneider A (eds) Sudden Infant Death Syndrome. Academic Press, London, pp 263-269

29. McCulloech K, Brouillette RT, Guzzetta AJ, Hunt CE 1982 Arousal responses in near-miss sudden infant death syndrome and in normal infants. $J$ Pediatr 101:911-917

30. van der Hal AL, Rodriguez AM, Sargent CW, Platzker ACG, Keens TG 1985 Hypoxic and hypercapneic arousal responses and prediction of subsequent apnea in apnea of infancy. Pediatrics 75:848-854

31. Hunt CE, Brouillette RT 1987 Sudden infant death syndrome: 1987 perspective. J Pediatr 110:669-678

32. Steinschneider A 1972 Prolonged apnea and the sudden infant death syndrome: clinical and laboratory observations. Pediatrics 50:646-654 